\title{
Just go to training!
}

There are so many training opportunities today: webinars offered by the US Department of Agriculture, Office of Laboratory Animal Welfare (OLAW), National Association for Biomedical Research, Laboratory Animal Welfare Training Exchange and equipment vendors; branch, regional and the annual national meeting of the American Association for Laboratory Animal Science (AALAS); topic-focused meetings by American College of Laboratory Animal Medicine and Laboratory Animal Management Association; and more. Web-based technology and traditional methods all offer lab animal personnel a variety of ways to 'go' and learn more, do better and accomplish objectives with animal studies.

Whenever I receive an announcement about a training opportunity, whether by snail mail or email, I wonder how I can work it into my schedule. And I consider how the topic relates to the interests of the persons with whom I work. For example, when I learned of the online workshop "Introduction to Institutional Animal Care and Use Committees" presented by the Massachusetts Society for Medical Research, I registered the two public members of my IACUC. I said, "You're going, but virtually." I regularly register for OLAW workshops myself, and I invite other IACUC members to 'go' and watch them with me (coffee and pastries help to entice, I don't mind saying) and then discuss the material presented. I also circulate announcements related to training to my vet tech students so that they can learn from other experienced persons in the field.

Not so long ago, the Southern California branch of AALAS (SCB-AALAS) held a hands-on workshop on mouse anesthesia, surgical techniques and osmotic pump implantation. I invited my vet tech students to 'go', thinking it would be a means to augment their education with very current and relevant material. Not all of my students are considering a career in lab animal medicine, but many want to learn more about the field. Some students expressed interest in attending the workshop, and I asked the SCB-AALAS organizers if they could offer a discounted registration fee (don't we all remember being cash-poor in college?). As a training coordinator, I advocated on their behalf. The organizers graciously granted my request, and two students were able to arrange their busy lives to attend the workshop on a Saturday morning. Yes, Saturday!

Here is what they wrote to reflect on the experience (both consented to my request to share their comments here). Neither had participated in such a workshop before; I think you can sense their enthusiasm.

"This workshop was an amazing experience because we were given valuable information involving anesthetic and analgesic procedures with rodents, particularly rats. It was definitely helpful because they take safety very seriously compared to a small animal hospital because they are using biohazards that could be very harmful if they accidentally poke themselves with a needle. They showed us different techniques to use when administering injections to reduce the chance of an accident. Before we went in the surgery room, we had to put on a lot of PPE [personal protective equipment] and perform aseptic technique when preparing the rat for surgery. All the rats were euthanized prior to our training because in reality we cannot perform surgery, but they showed us every step in doing an ALZET pump implantation. I really liked it because they would come by and check on you every so often and give you tips on how to do things more efficiently, so it is easier for you to do and understand. They gave us a DVD on different surgery procedures done on rodents, so now I can have something to refer to if I ever come across one of the surgeries. It was a great workshop and it gave me an idea of what to expect. Thank you for letting me know about this. I had a really great time."

"The rodent workshop held by AALAS on last Saturday was awesome! We learned to infuse with a 'miniature pump' which enables continuous delivery of bioactive compounds to mice or rats. The pump can be implanted IP [intraperitoneally] or SC [subcutaneously]. Veterinarians can put experimental agents in the pump, and when implanted, the drug is infused continuously for a prolonged period of time up to 6 weeks, thereby reducing stress responses resulting from frequent handling and repeated dosing. This 'miniature pump' is also a product from lab animal research. There were around 20 students with 6 instructors. Firstly, the veterinarian demonstrated how to do an aseptic surgery on the rat. He explained everything in great detail from using the different anesthetic gases to different suture patterns. Then, each student was given a euthanized rat and we did surgery ourselves. It was totally a good experience and whenever we had questions, we could ask the instructors. AALAS is a really good organization that promotes education and training. With better training, we could reduce the suffering of the animals and could lead to more successful research."

My message, then, is fairly simple: There are so many training opportunities. Take advantage of them, and just go to training, for gosh sakes! We all have to negotiate time and cost. But, remember: "nothing ventured, nothing gained." Find out whether your requirements can be accommodated so that you can participate. Like my students, you are likely to learn a lot! So, 'go!' 